\title{
Investigation of Emulsion Formation in Solvent Washing in the Caustic-Side Solvent Extraction (CSSX) Process
}

\section{June 2002}

Prepared by

Joseph F. Birdwell, Jr., Kimberly K. Anderson, and D. E. Hobson 


\section{DOCUMENT AVAILABILITY}

Reports produced after January 1, 1996 are generally available free via the U.S. Department of Energy (DOE) Information Bridge.

Web site http://www.osti.gov/bridge

Reports produced before January 1, 1996 may be purchased by members of the public from the following source.

National Technical Information Service

5285 Port Royal Road

Springfield, VA 22464

Telephone 703-605-6000 (1-800-553-6847)

TDD 703-487-4639

Fax 703-605-6900

E-mail info@ntis.fedworld.gov

Web site http://www.ntis.gov/support/ordernowabout.htm

Reports are available to DOE employees, DOE contractors, Energy Technology Data Exchange (ETDE) representatives, and International Nuclear Information System (INIS) representatives from the following source.

Office of Scientific and Technical Information

P.O. Box 62

Oak Ridge, TN 37831

Telephone 865-576-8401

Fax 865-576-5728

E-mail reports@adonis.osti.gov

Web site http://www.osti.gov/contact.html

This report was prepared as an account of work sponsored by an agency of the United States Government. Neither the United States Government nor any agency thereof, nor any of their employees, makes any warranty, express or implied, or assumes any legal liability or responsibility for the accuracy, completeness, or usefulness of any information, apparatus, product, or process disclosed, or represents that its use would not infringe privately owned rights. Reference herein to any specific commercial product, process, or service by trade name trademark, manufacturer, or endorsement recommendation, or favoring by the United States Government or any agency thereof. The views and opinions of authors expressed herein do not necessarily state or reflect those of the United States Government of any agency thereof. 
ORNL/TM-2002/126

Nuclear Science and Technology Division

\title{
Investigation of Emulsion Formation in Solvent Washing in the Caustic-Side Solvent Extraction (CSSX) Process
}

\author{
Joseph F. Birdwell, Jr. \\ Kimberly K. Anderson \\ D. E. Hobson
}

Date Published: June 2002

\author{
Prepared for the \\ DOE Office of Environmental Management \\ and the \\ Tanks Focus Area Salt Processing Project \\ DOE Office of Science and Technology \\ Prepared by \\ OAK RIDGE NATIONAL LABORATORY \\ Oak Ridge, Tennessee 37831-6285 \\ managed by \\ UT-BATTELLE, LLC \\ for the \\ U.S. DEPARTMENT OF ENERGY \\ under contract DE-AC05-00OR22725
}





\section{CONTENTS}

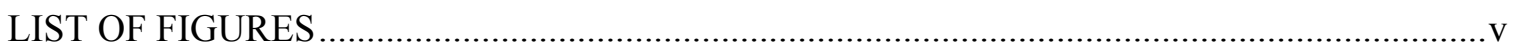

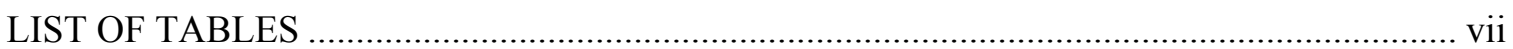

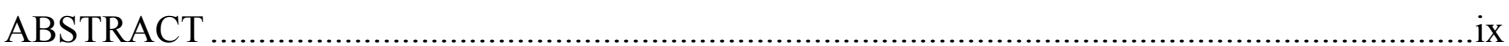

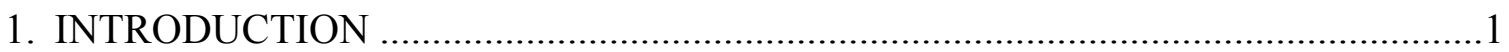

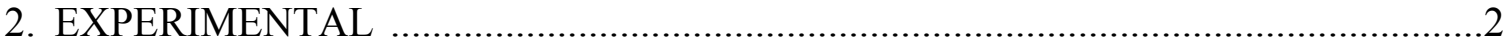

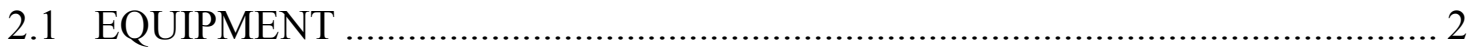

2.1.1 Investigation of Factors Affecting Phase Separation.................................. 2

2.1.2 Phase Separation Evaluation in a Centrifugal Contactor.............................. 3

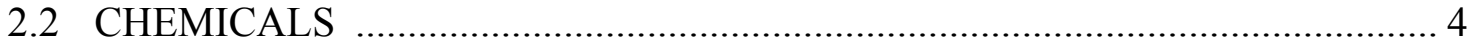

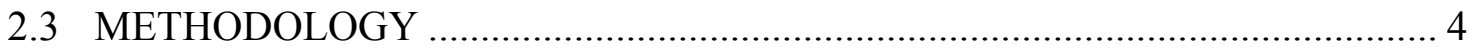

2.3.1 Investigation of Factors Affecting Phase Separation................................... 4

2.3.2 Phase Separation Evaluation in a Centrifugal Contactor ............................ 10

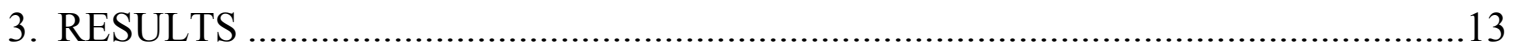

3.1 Investigation of Factors Affecting Phase Separation ...................................... 13

3.2 Phase Separation Evaluation in a Centrifugal Contactor .................................. 14

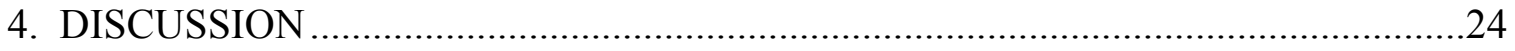

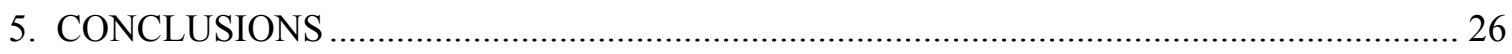

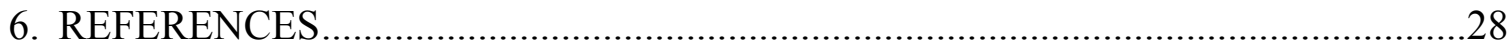





\section{LIST OF FIGURES}

Figure
Equipment configuration for preequilibration of solvent

Page

Equipment configuration for contactor phase separation test...

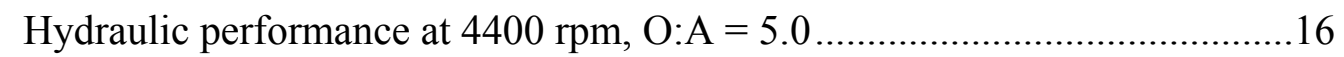

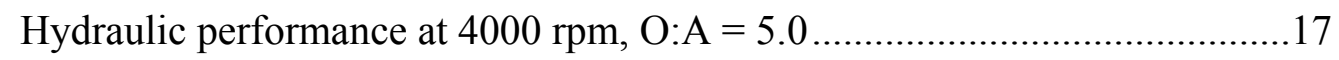

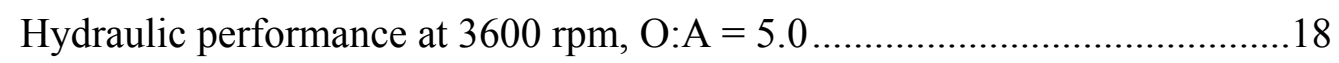

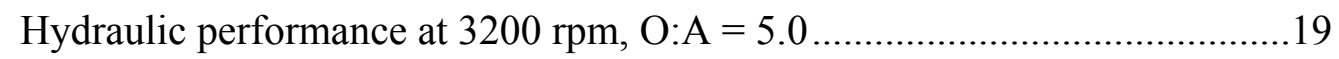

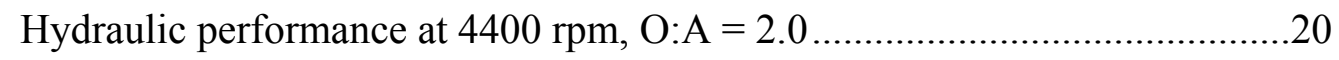

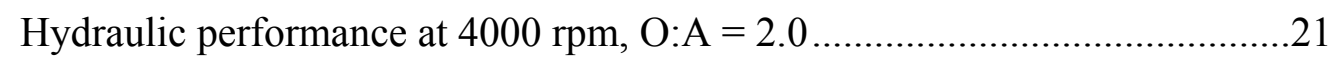

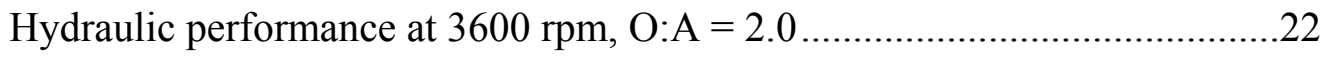

Hydraulic performance at $3200 \mathrm{rpm}, \mathrm{O}: \mathrm{A}=2.0$. 



\section{LIST OF TABLES}

Table

\begin{abstract}
Composition of CSSX solvent .....................................................................
\end{abstract}
Experimental treatments in the emulsification factor test ..................................6

Summary of solvent compositions used in emulsification factor testing ..........9

Dispersion number results from full-factorial experiment............................. 14

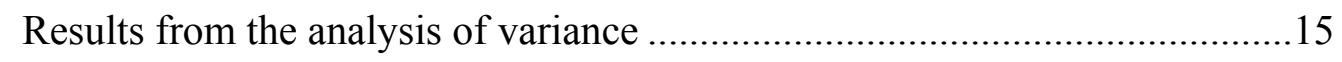

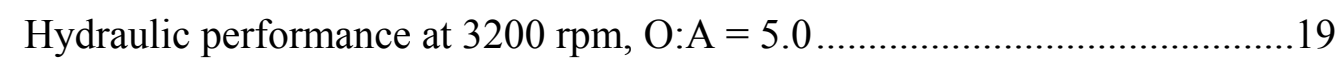

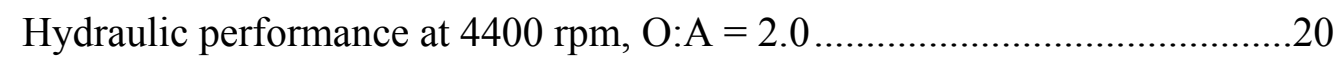

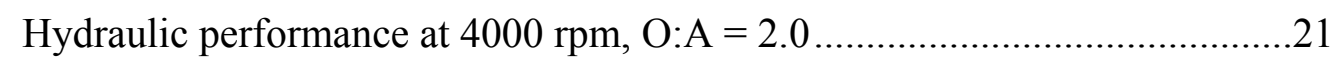

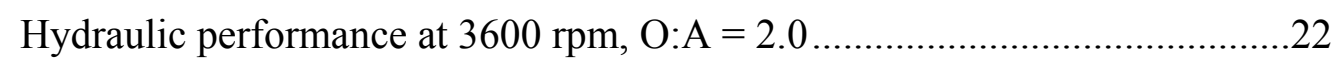

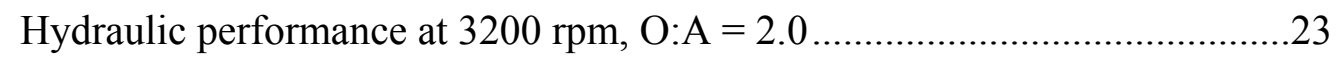





\begin{abstract}
The effects on phase separation and emulsion formation of variables present in the caustic washing of solvent in the caustic-side solvent extraction process have been investigated. The evaluation program was performed in two experiments; results of the first experiment were used to determine conditions for the second test. In the first experiment, the effects of solvent degradation product concentrations (4-sec- butylphenol and dioctylamine), wash solution $\mathrm{NaOH}$ concentration, and solvent-to-wash solution volume ratio (O:A) on phase separation were examined. Phase separation performance was quantified in terms of the dimensionless dispersion number, which is also a variable used in the prediction of centrifugal contactor performance by computational means. In the second experiment, phase separation performance in a 5-cm centrifugal contactor was investigated as a function of contactor speed, aqueous-phase $\mathrm{NaOH}$ concentration, and solvent-to-wash volume ratio. Separation performance was quantified in terms of the maximum throughput that could be achieved without resulting in $>1 \%$ contamination of either effluent phase with the opposing phase.

Results of the first experiment indicated that none of the variables considered affected phase separation performance at a 95\% significance level and that dioctylamine concentration was the only single factor that affected phase separation at a $90 \%$ significance level. The results do indicate $90 \%$ significance for interaction effects between $\mathrm{NaOH}$ concentration and $\mathrm{O}: \mathrm{A}$ and between $\mathrm{NaOH}$ concentration and 4-secbutylphenol concentration. However, none of the dispersion numbers obtained were inconsistent with values obtained in previous studies of CSSX solvent formulations.

Results of contactor performance tests indicated that acceptable phase separation was achieved at relatively high throughputs over a range of O:A ratios and wash solution $\mathrm{NaOH}$ concentrations. Emulsion formation during contactor operation was observed only under off-normal conditions.

Taken together, the results of the work described in this report indicate that from the perspective of phase separation efficiency, CSSX solvent washing can be performed over a range of conditions. Consequently, contaminant removal considerations should not be affected by hydraulic performance concerns in the selection of parameters for solvent treatment.
\end{abstract}




\section{INTRODUCTION}

This report describes two sets of experiments that were performed to determine the extent to which variables present in the washing of caustic-side solvent extraction (CSSX) solvent affect separation of the solvent and wash solutions and to investigate the tendency of emulsions to form during washing in a centrifugal contactor. In the event that solvent washing was found to be affected by emulsion formation, the ultimate objective of the test program was to determine a range of conditions over which emulsion formation could be avoided. Prior to the reported work, solvent washing had been demonstrated in conjunction with a CSSX flowsheet test in which actual tank waste was

processed. ${ }^{1}$ However, the earlier demonstration was performed at low throughputs using 2 -cm centrifugal contactors. In addition, the solvent used had undergone a very limited irradiation period; consequently the levels of degradation products were low.

The CSSX process has been developed as an alternative means of selectively removing cesium from high-level radioactive waste that has been generated in the production of nuclear materials. The target application for CSSX is the removal of cesium from tank waste that is stored at the U.S. Department of Energy (DOE) Savannah River Site (SRS). In its stored alkaline form, the waste consists of soluble salt and insoluble sludge. Since 1996, DOE has been vitrifying (converting to glass) the sludge component of the waste to produce a waste form that is sufficiently stable to permit disposal in a geologic repository. As a result of a recent evaluation of treatment technologies, DOE has decided to implement the CSSX process for treatment of the soluble salt component of the stored waste. ${ }^{2}$

The first experiment performed was a full-factorial, fully randomized, two-level design in which the effects of washing parameters on phase separation performance were evaluated by analysis of variance (ANOVA). Variables considered in this experiment were the concentrations of the primary solvent degradation products 4-sec- butylphenol (4SBP) and dioctylamine (DOA), the concentration of $\mathrm{NaOH}$ in the wash solution, and the volume ratio of organic solvent to aqueous wash solution (O:A). Effects were measured in terms of the dispersion number, a dimensionless term that indicates the relative tendency of a dispersion to separate into its component phases. In the 
experiment, each variable was assigned two values (levels): a high and a low (or zero) value. All possible combinations of variable values were evaluated. The configuration was the same for all test conditions, and the temperature was controlled throughout the test to eliminate it as a variable. The experiment was randomized by performing test combinations in random order, thereby mitigating effects from uncontrolled or unidentified variables.

The second experiment was a conventional determination of contactor hydraulic performance in which the maximum throughput that could be obtained with $<1 \%$ crossphase contamination of either product stream was determined as a function of rotor speed, aqueous-phase $\mathrm{NaOH}$ concentration, and $\mathrm{O}$ :A flow ratio. The solvent used in this experiment contained high levels of both solvent degradation products in order to determine conservative limits for contactor operation, based on results of the first experiment. Rotor speed values were limited to a range that has been found to provide good phase separation and mass transfer performance in previous tests under CSSX extraction, scrubbing, and stripping conditions.

\section{EXPERIMENTAL}

\subsection{EQUIPMENT}

\subsubsection{Investigation of Factors Affecting Phase Separation}

\subsubsection{Glassware}

Glassware used in the creation of dispersions and in the determination of phase separation times comprised standard 100-mL graduated cylinders of borosilicate glass. All were equipped with ground-glass stoppers. In a manner consistent with prior dispersion number determinations, all glassware was washed by rinsing three times with tap water, rinsing three times with demineralized water, rinsing twice with ethanol, and rinsing twice with acetone. The glassware was allowed to air dry or was dried with a stream of dry nitrogen or argon. 


\subsubsection{Temperature bath}

The water bath used to maintain the temperature of phase separation samples consisted of an open-top plexiglass tray into which a recirculating heater was submerged. The heater was obtained from Cole-Parmer Instrument Co. (Vernon Hills, IL, catalog no. P-21423) and provided control within $\pm 0.1^{\circ} \mathrm{C}$. Temperatures were verified periodically using a digital thermometer that was obtained from the Cole-Parmer Instrument Co. (catalog no. P-90003-00). The thermometer used had been certified to have resolution to within $0.1^{\circ} \mathrm{C}$ up to $199.9^{\circ} \mathrm{C}$.

\subsubsection{Phase Separation Evaluation in a Centrifugal Contactor}

\subsubsection{Centrifugal contactor}

The 5-cm centrifugal contactor used in the subject test program was obtained from CINC, Inc. (Carson City, NV), as a standard-design item (model V-2) having a rotor with a diameter of $5 \mathrm{~cm}$. The contactor was powered by a 110-V AC single-phase motor, which was controlled by a variable-frequency drive. The maximum frequency of the drive controller was $100 \mathrm{~Hz}$, which corresponds to a nominal rotor speed of $6000 \mathrm{rpm}$. All wetted contactor components had been fabricated from $316 \mathrm{~L}$ stainless steel, tetrafluoroethylene (TFE) Teflon ${ }^{\mathrm{TM}}$, or TFE-encapsulated Viton ${ }^{\mathrm{TM}}$.

The unit used was equipped with a modified rotor housing bottom. As received from the vendor, the housing bottom had eight vanes, which spiral inward toward the axis of the unit in the direction of rotation. To make the configuration typical of contactor designs from Oak Ridge National Laboratory (ORNL), Argonne National Laboratory, and Savannah River Technology Center, a housing bottom with straight radial vanes was fabricated. This modification had been implemented successfully in previous CSSX process testing. ${ }^{3}$

Throughout phase separation testing the contactor was operated using an aqueous weir having a diameter of 0.975 in.

\subsubsection{Pumps}

All solution transfers were performed using piston-type metering pumps (Fluid Metering Inc., Model QV-2) with a maximum nominal throughput of $1296 \mathrm{~mL} / \mathrm{min}$. In previous CSSX-related tests, the maximum throughput achieved using these pumps was 
approximately $1000 \mathrm{~mL} / \mathrm{min}$. The pump heads were equipped with 300 series stainless steel sleeves and ceramic pistons.

\subsubsection{Vessels and tubing}

The vessels used to supply and receive solutions (15-L capacity high-density polyethylene tanks) were obtained from VWR Scientific Products (Oak Ridge, TN, catalog no. 60464-043). All tubing used during testing was PFA Teflon ${ }^{\mathrm{TM}}$; all tubing fittings were constructed from $304 \mathrm{~L}$ stainless steel.

\subsection{CHEMICALS}

The CSSX solvent used in the subject test, which was the optimized formulation having the composition listed in Table 1, was obtained from the Chemical Sciences Division at ORNL.

SRS waste supernatant simulant was prepared according to SRS procedure WSRC-RP-2000-00361, Rev. 0, and had the composition listed in that document for "average" SRS supernatant simulant. ${ }^{4}$ Stable cesium was added to the supernatant as cesium nitrate to a nominal concentration of $0.00014 \mathrm{M}$.

Scrub (0.05 $\left.M \mathrm{HNO}_{3}\right)$ and strip (0.001 $\left.M \mathrm{HNO}_{3}\right)$ aqueous solutions used to treat the solvent prior to its use in testing were prepared using $0.10 \mathrm{~N} \mathrm{HNO}_{3}$ (procured from J. T. Baker Co.) that was diluted to concentration using deionized water. Sodium hydroxide solutions used in the washing study were prepared in a similar manner using a standard $0.1 \mathrm{~N} \mathrm{NaOH}$ solution (ACS reagent grade, procured from J. T. Baker Co.).

\subsection{METHODOLOGY}

\subsubsection{Investigation of Factors Affecting Phase Separation}

A fully-randomized, two-level, four-factor complete factorial experiment was performed to evaluate the significance of the effects of solvent degradation product concentration (4SBP and DOA), wash solution $\mathrm{NaOH}$ concentration, and solvent-toaqueous volume ratio (O:A) on phase separation as an indicator of emulsion formation tendency. Use of a full-factorial design allows both the examination of single-factor

effects and evaluation of 2-, 3-, and 4-factor interaction effects. ${ }^{5}$ Two levels (values) 
Table 1. Composition of CSSX solvent

\begin{tabular}{|l|c|}
\hline \multicolumn{1}{|c|}{ Component } & Concentration \\
\hline $\begin{array}{l}\text { Calix(4)arene-bis-(tert-octylbenzo-crown-6) } \\
\text { (BOBCalixC6) }\end{array}$ & $0.007 \mathrm{M}$ \\
\hline $\begin{array}{l}\text { (2,2,3,3-Tetrafluoropropoxy)-3-(4-sec-butylphenoxy)-2- } \\
\text { propanol } \\
\text { (Cs-7SB) }\end{array}$ & $0.75 \mathrm{M}$ \\
\hline Trioctylamine & $0.003 \mathrm{M}$ \\
\hline Isopar ${ }^{\circ} \mathrm{L}$ & Balance \\
\hline
\end{tabular}

were established for each of the four variables under consideration, and one treatment was conducted for each possible combination of variable levels. In addition, four treatments (i.e., parameter combinations) were selected at random for duplication to obtain and estimate the experimental error, which is needed to quantify the significance of the single and multifactor interaction effects. Treatments are listed in Table 2, which also indicates the experiment sequence and the treatments that were duplicated to estimate the experimental error. Variable values are listed in the footnotes to the table.

Randomization was used to mitigate any minor deviations in experiment conditions or procedures between treatments. In the experiment performed, each treatment was assigned a number, and numbers were drawn at random to determine the order in which the treatments would be performed.

Prior to the experiment, 3.0 L of the optimized CSSX solvent was pretreated by equilibration under conditions present in the extraction, scrubbing, and stripping sections of the CSSX cascade. The solvent inventory that was treated included volumes needed for both the evaluation of factors affecting phase separation and for contactor hydraulic testing. 
Table 2. Experimental treatments in the emulsification factor test

\begin{tabular}{|c|c|c|c|c|c|c|}
\hline $\begin{array}{c}\text { Treatment } \\
\text { No. }\end{array}$ & $\begin{array}{c}\text { 4SBP } \\
\text { condition }^{a}\end{array}$ & $\begin{array}{c}\text { DOA } \\
\text { condition }^{b}\end{array}$ & $\begin{array}{c}\text { Wash solution } \\
\mathrm{NaOH} \\
\text { condition }^{c} \\
\end{array}$ & $\begin{array}{c}\text { Washing } \\
\text { O:A volume } \\
\text { ratio }_{d}\end{array}$ & $\begin{array}{c}\text { Treatment } \\
\text { order }\end{array}$ & $\begin{array}{c}\text { Assigned } \\
\text { graduated } \\
\text { cylinder }\end{array}$ \\
\hline 1 (null) & - & - & - & - & 8 & 1 \\
\hline 2 & + & - & - & - & 5 & 4 \\
\hline 3 & - & + & - & - & 12 & 4 \\
\hline $3^{e}$ & - & + & - & - & 16 & 4 \\
\hline 4 & - & - & + & - & 6 & 4 \\
\hline 5 & - & - & - & + & 7 & 2 \\
\hline 6 & + & + & - & - & 10 & 3 \\
\hline $6^{e}$ & + & + & - & - & 3 & 3 \\
\hline 7 & + & - & + & - & 20 & 3 \\
\hline 8 & + & - & - & + & 14 & 2 \\
\hline 9 & - & + & + & - & 15 & 1 \\
\hline 10 & - & - & + & + & 9 & 2 \\
\hline 11 & - & + & - & + & 19 & 3 \\
\hline $11^{e}$ & - & + & - & + & 17 & 3 \\
\hline 12 & + & + & + & - & 4 & 3 \\
\hline 13 & + & - & + & + & 1 & 1 \\
\hline 14 & + & + & - & + & 13 & 2 \\
\hline 15 & - & + & + & + & 11 & 4 \\
\hline 16 & + & + & + & + & 2 & 1 \\
\hline $16^{e}$ & + & + & + & + & 18 & 1 \\
\hline
\end{tabular}

${ }^{a}$ If 4-sec butylphenol = "_“", concentration $=0$; if 4-sec butylphenol = "+”, concentration $=15$ ppm.

${ }^{b}$ If dioctylamine $=$ “_"“, concentration $=0$; if dioctylamine $=$ "+ + , concentration $=120 \mathrm{ppm}$.

${ }^{c}$ If $\mathrm{NaOH}=$ "_.", concentration $=0.001 \mathrm{M}$; if $\mathrm{NaOH}=$ "+", concentration $=0.03 \mathrm{M}$.

${ }^{d}$ If organic-to-aqueous ratio is designated "_-", $\mathrm{O}: \mathrm{A}=0.5$; if designation is “+”, $\mathrm{O}: \mathrm{A}$ ratio is 2.0.

${ }^{e}$ Duplicate treatment for error determination.

The solvent was first contacted with simulated SRS tank waste supernatant and scrub solutions at the flow ratios specified for the extraction section of the current CSSX baseline flowsheet. ${ }^{6}$ Pretreatment was performed using a 5 -cm centrifugal contactor configured in the test loop shown in Fig. 1. All pretreatment operations (extraction, scrubbing, and stripping) were performed with the contactor operating at $3600 \mathrm{rpm}$. The combined aqueous solution flow rate maintained during extraction pretreatment was 812 $\mathrm{mL} / \mathrm{min}$ (nominal); the solvent flow rate was a nominal $250 \mathrm{~mL} / \mathrm{min}$.

After processing the solvent inventory under extraction conditions, the contactor was disassembled and all components and ancillary items (pumps, tubing, etc.) were rinsed twice with $0.05 \mathrm{MHNO}_{3}$. Prior to reassembling the equipment, the $\mathrm{pH}$ of the wash solution from the second rinse was verified to be that of the scrub solution (indicating removal of any tramp simulant solution). After reassembly of the contactor loop, the 


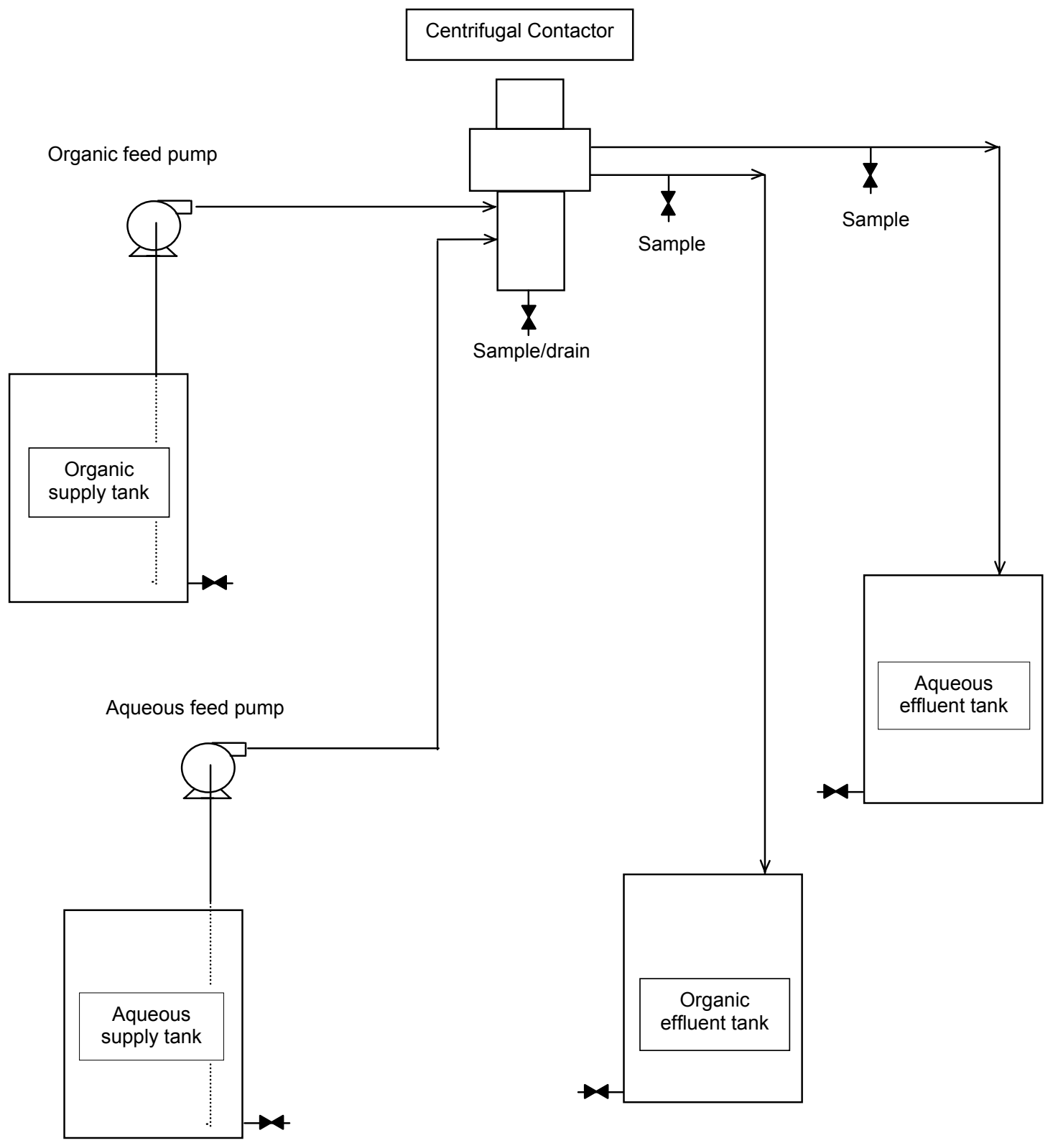

Fig. 1. Equipment configuration for preequilibration of solvent. 
solvent collected from the extraction pretreatment operation was contacted with scrub solution ( $\left.0.05 \mathrm{M} \mathrm{HNO}_{3}\right)$. Flow rates maintained during the scrubbing operation were $250 \mathrm{~mL} / \mathrm{min}$ for the solvent and $50 \mathrm{~mL} / \mathrm{min}$ for the scrub solution. To verify that the scrub was effective in reducing the $\mathrm{pH}$ of the solvent to a level suitable for stripping, the $\mathrm{pH}$ of the aqueous stream was verified to be less than 3 after the scrubbing operation was completed.

At the conclusion of the scrubbing pretreatment step, the contactor and other equipment were rinsed with $0.001 M \mathrm{HNO}_{3}$ (strip solution) using the procedure followed after extraction pretreatment. After verifying that the $\mathrm{pH}$ of the rinsate was approximately that of the strip solution, the equipment was reassembled. The solvent collected from the scrubbing pretreatment was contacted with strip solution using the centrifugal contactor. The flow rates maintained during the stripping pretreatment were the same as those that were applied during scrubbing.

Of the $3 \mathrm{~L}$ of solvent collected from pretreatment, $700 \mathrm{~mL}$ was removed for use in the factorial experiment. This volume was subdivided into one volume of $350 \mathrm{~mL}$ and two volumes of $175 \mathrm{~mL}$. One of the $175-\mathrm{mL}$ volumes, labeled "Solvent A," was stored without addition of degradation products. For the solution designated "Solvent C," 21.00 $\mathrm{mg}$ of DOA were added to the other $175-\mathrm{mL}$ solvent volume, yielding a DOA concentration of $120 \mathrm{ppm}$. (Throughout the reported work, "parts per million" or "ppm" is defined as the ratio of the mass of solute to the volume of solvent plus solute. Therefore, $1 \mathrm{ppm}$ is equal to $1 \mathrm{mg}$ solute in $1 \mathrm{~L}$ of solution.) To the $350-\mathrm{mL}$ sample of pretreated solvent was added $5.25 \mathrm{mg}$ of $4 \mathrm{SBP}$ to yield a concentration of $15 \mathrm{ppm}$. A $175-\mathrm{mL}$ volume was collected from this solvent and labeled "Solvent B." To the remaining solvent solvent volume was added $21.00 \mathrm{mg}$ DOA to produce "Solvent D." The final degradation product concentrations in the four solvent aliquots used in emulsification factor testing are summarized in Table 3. The concentrations of DOA and 4SBP were selected based on results reported from batch irradiation tests using the baseline CSSX solvent. ${ }^{7}$

According to the treatment conditions listed in Table 2, volumes of the prescribed solvent and $\mathrm{NaOH}$ solution were dispersed in one of four glass graduated cylinders 
Table 3. Summary of solvent compositions used in emulsification factor testing.

\begin{tabular}{ccc}
\hline Solvent Designation & DOA concentration, $\mathrm{ppm}$ & 4SBP concentration, $\mathrm{ppm}$ \\
\hline A & 0 & 0 \\
$\mathrm{~B}$ & 0 & 15 \\
$\mathrm{C}$ & 120 & 0 \\
$\mathrm{D}$ & 120 & 15 \\
\hline
\end{tabular}

$(100 \mathrm{~mL})$ with ground-glass stoppers. To eliminate bias due to any cylinder variations, each graduate was assigned a number from one to four, and numbers were selected at random to determine which would be used in each treatment. At the lower O:A ratio (0.5), a 50-mL volume of the aqueous solution was contacted with $25 \mathrm{~mL}$ of the specified solvent. At the higher O:A ratio (2.0), the volumes of the two solutions were reversed. Prior to agitation, the position of the phase boundary (interface) was recorded using millimeter scales that were attached to each graduate. For temperature control, all solutions were allowed to reach thermal equilibrium in a water bath maintained at $25.0^{\circ} \mathrm{C}$ prior to mixing. In all cases, dispersions were formed by manually shaking the aqueous and organic solutions for $20 \mathrm{~s}$, suspending agitation (shaking) for $10 \mathrm{~s}$, and resuming agitation for an additional $20 \mathrm{~s}$. The phase break time was determined by measuring the time required for the interface to return to its original position after cessation of the second agitation period. Since the entire liquid height was found to become dispersed as a result of agitation, this height was measured and was used in the calculation of dispersion numbers, according to the expression

$$
N_{D i}=\frac{1}{t_{b}} \sqrt{\frac{z}{g}},
$$

where $t_{b}$ is the break time in seconds, $\mathrm{z}$ is the dispersion band height in feet, and $\mathrm{g}$ is acceleration due to gravity, taken to be $32.172 \mathrm{ft} / \mathrm{s}^{2}$ (Ref. 8). Break-time determinations were repeated three times with reequilibration at $25^{\circ} \mathrm{C}$ between each replication.

To determine whether a single-factor or multifactor interaction effect was significant with respect to phase separation performance, an ANOVA was performed in which the 
yields from the treatments (i.e., the dispersion numbers from each condition set) were used to calculate contrasts. In general terms, the contrast for a particular effect is calculated by adding the yields from treatments in which the effect was present and subtracting the yields from treatments in which the effect was absent. For example, the contrast for the single-factor DOA effect is calculated by adding the dispersion numbers from all treatments in which DOA was present at the high level $(120 \mathrm{ppm})$ and then subtracting the dispersion numbers from low-DOA (0-ppm) treatments. Contrasts are squared to eliminate sign differences, since the direction of contrast (positive or negative) is not addressed in the determination of significance.

An alternative approach to calculating contrasts is the method of Yates, in which yields are tabulated by treatment combination, and yield pairs are added or subtracted according to location in the table. ${ }^{9}$ This approach generates the same contrast values as the technique described previously but is somewhat easier to follow when performing calculations manually. For this reason, the Yates method was used to analyze the data collected in the reported experiment, and a subset of the results was checked against those obtained by the other technique.

To determine the significance of each effect, the squared contrast is divided by the number of results (16 in this case) to obtain the mean square. An estimate of the mean square error is obtained by calculating the difference between yields from replicate treatments, squaring the differences, adding them, and dividing by the number of replicate pairs. To determine significance at some confidence level, the F-distribution value at this level is determined from an F-value table based on the number of degrees of freedom of the sample and the error estimate. The F-value is multiplied by the mean square error and is compared with the individual mean square contrasts. Effects having mean square contrasts exceeding the adjusted F-value are significant at the selected confidence level.

\subsubsection{Phase Separation Evaluation in a Centrifugal Contactor}

Based on the results of the emulsification factor evaluation, a solvent containing levels of both DOA and 4SBP was formulated from solvent that had been pretreated by contact with aqueous solutions under conditions present in the extraction, scrubbing, and 
stripping sections of the CSSX cascade. This solvent was placed into a single feed vessel, where it was continuously dispersed with an aqueous $\mathrm{NaOH}$ solution at a predetermined O:A ratio. The dispersion was maintained using a variable-speed mixer that was attached to a turbine-type impeller. The feed dispersion was delivered to a $5-\mathrm{cm}$ centrifugal contactor by piston-type metering pumps. In addition to the feed uptake lines, spare shaft-mounted impellers were submerged in the feed tank to promote mixing. The single-tank, parallel-pump configuration used (shown in Fig. 2) was selected to enable delivery of flow rates up to $2000 \mathrm{~mL} / \mathrm{min}$ using the same pump model that had been used in previous 5-cm contactor testing at ORNL, regardless of O:A ratio. Combining of the feed phases prior to pumping also mitigates changes in O:A ratio due to pumping variations (drift). Prior to performing contactor testing, dispersion samples were collected from the feed lines and were allowed to separate in order to verify that the desired phase ratio was being delivered to the contactor. In the test configuration dispersion formation occurred in the contactor mixing zone, not in the feed vessel.

Early in testing it was determined that at speeds in excess of $4400 \mathrm{rpm}$, flow entering the contactor via one of the two feed connections was discharged from the other (inactive) feed port. This phenomenon was believed to result from the transfer of momentum from the rotor to the feed stream, which impinges directly (normally) on the rotor due to the design of the contactor. Sufficient momentum is transferred that some fraction of the liquid is carried radially around the rotor to the inactive feed port without dropping below the level of that connection. (Both feed ports are oriented normally to the contactor housing and rotor at the same elevation, separated radially by $180^{\circ}$.)

Initial testing was performed at an O:A ratio of 5.0 using a $1 \mathrm{~m} M \mathrm{NaOH}$ solution. Phase separation performance was examined at a range of flow rates and at contactor speeds ranging from 3200 to $4400 \mathrm{rpm}$. For each combination of O:A ratio, aqueous $\mathrm{NaOH}$ concentration, and rotor speed, samples of both the aqueous and organic effluents from the contactor were collected at each flow rate. Samples were processed in a batchtype laboratory centrifuge to facilitate determination of opposing-phase carryover. At each O:A and $\mathrm{NaOH}$ condition, flows were increased until carryover in either effluent sample exceeded $1 \%$ by volume. When an endpoint was reached, the contactor speed and flow rate were reset and the sample evaluation procedure was repeated. 


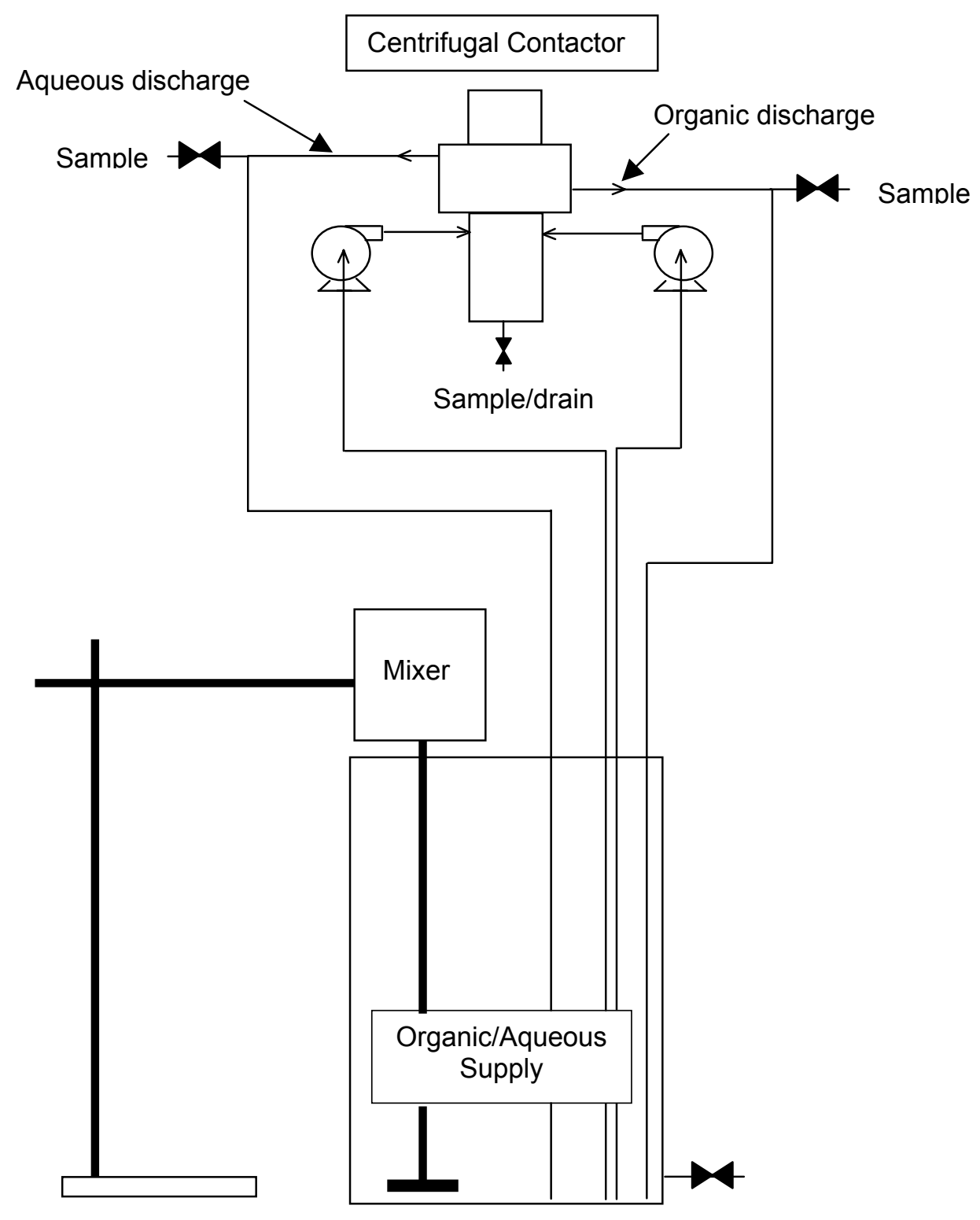

Fig. 2. Equipment configuration for contactor phase separation test. 
Tests were performed for $\mathrm{O}: \mathrm{A}$ ratios of 2.0 and 5.0 at aqueous $\mathrm{NaOH}$ concentrations of $1,2.5,5.0$, and $10 \mathrm{mM}$. The upper limit on $\mathrm{NaOH}$ concentration was based on information that surfactant impurities in the solvent are most effectively removed when the $\mathrm{NaOH}$ concentration is between 1 and $10 \mathrm{~m} M$ and the fact that phase separation at higher $\mathrm{NaOH}$ concentrations $(>10 \mathrm{~m} M)$ is favored over lower concentrations due to the increased difference in ionic potential between aqueous and organic phases.

\section{RESULTS}

\subsection{Investigation of Factors Affecting Phase Separation}

Phase separation times and the dispersion numbers calculated from them are listed in Table 4. The dispersion numbers are of the same order of magnitude and are consistent with values obtained for the baseline CSSX solvent under extraction, scrubbing, and stripping conditions. ${ }^{10}$ The values obtained are generally associated with acceptable phase separation performance; however, the values for Treatments 4 (high-NaOH effect), 12 (4SBP/DOA/NaOH interaction), and 15 (DOA/NaOH/O:A interaction) are indicative of borderline performance. It is important to note that a low dispersion number from any one treatment does not provide indication that the associated effect or interaction has a significant impact on phase separation at a high level of confidence. For an effect or interaction to be significant it must appear consistently whenever the associated factors are present in a treatment combination.

The ANOVA results (Table 5) indicate that none of the single-factor or interaction effects examined affect the dispersion number result at a confidence level of $95 \%$. However, the single-factor DOA concentration effect and the two-factor $4 \mathrm{SBP} / \mathrm{NaOH}$ and $\mathrm{NaOH} / \mathrm{O}: \mathrm{A}$ interactions are significant at the $90 \%$ level (i.e., given the experimental error and the number of degrees of freedom in the experiment, these effects fall beyond the 90th percentile of a predicted normal distribution of results).

As a check on the reliability of the data, the error estimate (mean square error) used to calculate distribution statistics was calculated by two methods. In the primary method (used to calculate the distribution), the mean square error was calculated from the four 
Table 4. Dispersion number results from full-factorial experiment

\begin{tabular}{|c|c|c|c|c|c|c|c|}
\hline Treatment & 4 SBP & DOA & NaOH & O:A ratio & $\begin{array}{c}\text { Average separation } \\
\text { time (s) }\end{array}$ & $\begin{array}{c}\text { Dispersion band } \\
\text { height (in.) }\end{array}$ & $N_{D i}$ \\
\hline 1 & - & - & - & - & 149.67 & 5.75 & 0.000815 \\
\hline 2 & + & - & - & - & 182.33 & 5.50 & 0.000655 \\
\hline 3 & - & + & - & - & 170.33 & 5.50 & 0.000701 \\
\hline $3^{a}$ & - & + & - & - & 148.00 & 5.50 & 0.000806 \\
\hline 4 & - & - & + & - & 321.50 & 5.50 & 0.000371 \\
\hline 5 & - & - & - & + & 149.67 & 5.625 & 0.000807 \\
\hline 6 & + & + & - & - & 231.00 & 5.625 & 0.000523 \\
\hline $6^{a}$ & + & + & - & - & 212.00 & 5.625 & 0.000569 \\
\hline 7 & + & - & + & - & 160.00 & 5.625 & 0.000721 \\
\hline 8 & + & - & - & + & 210.00 & 5.625 & 0.000575 \\
\hline 9 & - & + & + & - & 250.50 & 5.75 & 0.000487 \\
\hline 10 & - & - & + & + & 166.00 & 5.625 & 0.000727 \\
\hline 11 & - & + & - & + & 229.00 & 5.625 & 0.000527 \\
\hline $11^{a}$ & - & + & - & + & 165.50 & 5.625 & 0.000729 \\
\hline 12 & + & + & + & - & 351.00 & 5.625 & 0.000344 \\
\hline 13 & + & - & + & + & 140.67 & 5.75 & 0.000868 \\
\hline 14 & + & + & - & + & 245.50 & 5.625 & 0.000492 \\
\hline 15 & - & + & + & + & 264.33 & 5.50 & 0.000452 \\
\hline 16 & + & + & + & + & 159.33 & 5.75 & 0.000766 \\
\hline $16^{a}$ & + & + & + & + & 169.00 & 5.75 & 0.000722 \\
\hline
\end{tabular}

${ }^{a}$ Replicate observation included for error determination.

treatment combinations for which replicate experiments were performed. In the secondary method, the error was assumed to be the mean of the sums of squares of threeand four-factor interaction effects. This method is commonly used when there are no replicates from which to calculate error. As indicated in the footnotes to Table 5, the error estimates obtained by the two methods are in close agreement (within $\approx 22 \%$ ).

\subsection{Phase Separation Evaluation in a Centrifugal Contactor}

Results from phase separation testing using the $5-\mathrm{cm}$ centrifugal contactor are presented in Figs. 3 through 10. Each figure displays phase separation performance as a function of throughput and aqueous $\mathrm{NaOH}$ concentration. Due to the volume of data 
Table 5. Results from the analysis of variance

\begin{tabular}{|c|c|c|c|c|c|}
\hline Effect $^{a}$ & $\begin{array}{l}\text { Yield } \\
\left(N_{D i}\right)\end{array}$ & Contrast & $\begin{array}{c}\text { Mean square } \\
\text { contrast }^{b}\end{array}$ & $\begin{array}{c}\text { Significant at 95\% } \\
\text { confidence }^{c}\end{array}$ & $\begin{array}{c}\text { Significant at } 90 \% \\
\text { confidence }^{d}\end{array}$ \\
\hline Null & 0.000815 & & & & \\
\hline $\mathrm{a}$ & 0.000655 & $1.10724 \mathrm{E}-05$ & $4.9039 \mathrm{E}-10$ & $\mathrm{~N}$ & $\mathrm{~N}$ \\
\hline $\mathrm{b}$ & 0.000701 & $-1.60139 \mathrm{E}-04$ & $1.0258 \mathrm{E}-07$ & $\mathrm{~N}$ & $\mathrm{Y}$ \\
\hline$a b$ & 0.000523 & $-2.17002 \mathrm{E}-05$ & $1.8836 \mathrm{E}-09$ & $\mathrm{~N}$ & $\mathrm{~N}$ \\
\hline $\mathrm{c}$ & 0.000371 & $-4.05505 \mathrm{E}-05$ & $6.5774 \mathrm{E}-09$ & $\mathrm{~N}$ & $\mathrm{~N}$ \\
\hline $\mathrm{ac}$ & 0.000754 & $1.62605 \mathrm{E}-04$ & $1.0576 \mathrm{E}-07$ & $\mathrm{~N}$ & $\mathrm{Y}$ \\
\hline $\mathrm{bc}$ & 0.000487 & $-7.82017 \mathrm{E}-06$ & $2.4462 \mathrm{E}-10$ & $\mathrm{~N}$ & $\mathrm{~N}$ \\
\hline $\mathrm{abc}$ & 0.000344 & $-6.64234 \mathrm{E}-05$ & $1.7648 \mathrm{E}-08$ & $\mathrm{~N}$ & $\mathrm{~N}$ \\
\hline $\mathrm{d}$ & 0.000807 & $7.02811 \mathrm{E}-05$ & $1.9758 \mathrm{E}-08$ & $\mathrm{~N}$ & $\mathrm{~N}$ \\
\hline $\mathrm{ad}$ & 0.000575 & $3.58533 \mathrm{E}-05$ & $5.1418 \mathrm{E}-09$ & $\mathrm{~N}$ & $\mathrm{~N}$ \\
\hline $\mathrm{bd}$ & 0.000527 & $-2.48022 \mathrm{E}-05$ & $2.4606 \mathrm{E}-09$ & $\mathrm{~N}$ & $\mathrm{~N}$ \\
\hline $\mathrm{abd}$ & 0.000492 & $1.14262 \mathrm{E}-04$ & $5.2223 \mathrm{E}-08$ & $\mathrm{~N}$ & $\mathrm{~N}$ \\
\hline $\mathrm{cd}$ & 0.000727 & $1.43587 \mathrm{E}-04$ & 8.2469E-08 & $\mathrm{N}$ & $\mathrm{Y}$ \\
\hline acd & 0.000868 & $1.78891 \mathrm{E}-05$ & $1.2801 \mathrm{E}-09$ & $\mathrm{~N}$ & $\mathrm{~N}$ \\
\hline bcd & 0.000452 & $4.13756 \mathrm{E}-06$ & $6.8478 \mathrm{E}-11$ & $\mathrm{~N}$ & $\mathrm{~N}$ \\
\hline abcd & 0.000766 & $6.08434 \mathrm{E}-05$ & $1.4808 \mathrm{E}-08$ & $\mathrm{~N}$ & $\mathrm{~N}$ \\
\hline
\end{tabular}

${ }^{a}$ Effect $\mathrm{a}=4 \mathrm{SBP}$; Effect $\mathrm{b}=$ DOA; Effect $\mathrm{c}=\mathrm{NaOH}$; Effect $\mathrm{d}=\mathrm{O}$ :A ratio.

${ }^{b}$ Mean squared error estimate from replicates $=1.40489 \mathrm{E}-08$; mean squared error estimate from 3 - and 4-factor interactions $=1.72055 \mathrm{E}-08$.

${ }^{c} 95 \% \mathrm{~F}=7.71$, test statistic at $95 \%$ confidence $=1.08317 \mathrm{E}-07$.

${ }^{d} 90 \% \mathrm{~F}=4.54$, test statistic at $90 \%$ confidence $=6.37822 \mathrm{E}-08$.

collected, data obtained at different rotor speeds and O:A values are presented in separate figures.

In all cases, the entrainment limit was reached by the presence of aqueous solution in organic effluent samples. The presence of organic-phase carryover in the aqueous effluent was detected only in samples that were collected after the accumulation of a foam plug in the organic discharge line. With respect to operating envelope, the most favorable results were obtained at rotor speeds of 4000 and $3600 \mathrm{rpm}$ coupled with an O:A value of 2.0 (Figures 8 and 9). At these conditions the throughput was limited by plugging of the organic discharge with foam. Foaming in the organic discharge was observed at low-to-moderate flows (less than $400-500 \mathrm{~mL} / \mathrm{min}$ ) under all conditions. The formation of plug foam flow typically occurred only at flow rates exceeding 700 


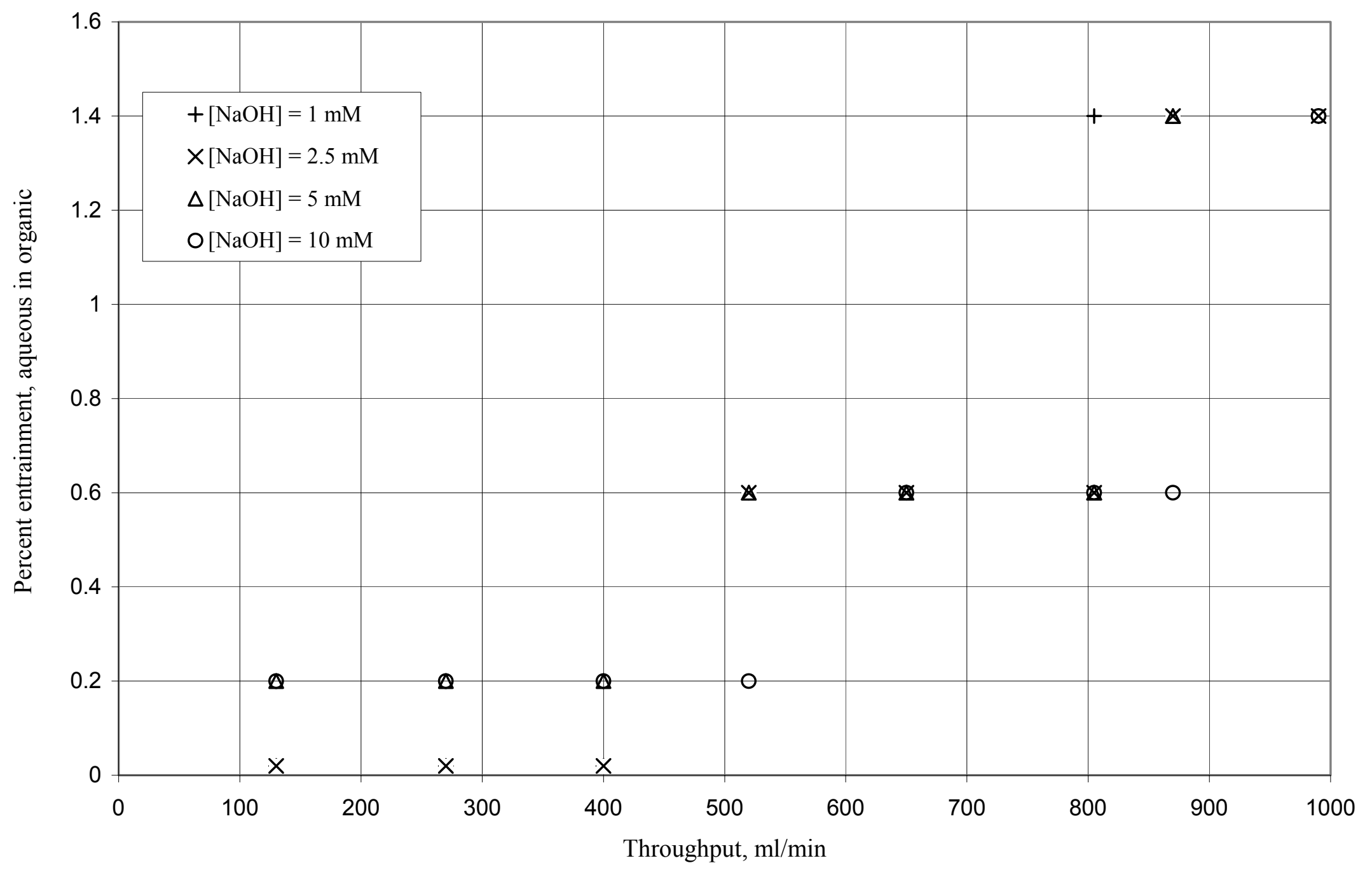

Fig. 3. Hydraulic performance at $4400 \mathrm{rpm}, \mathrm{O}: \mathrm{A}=5.0$ 


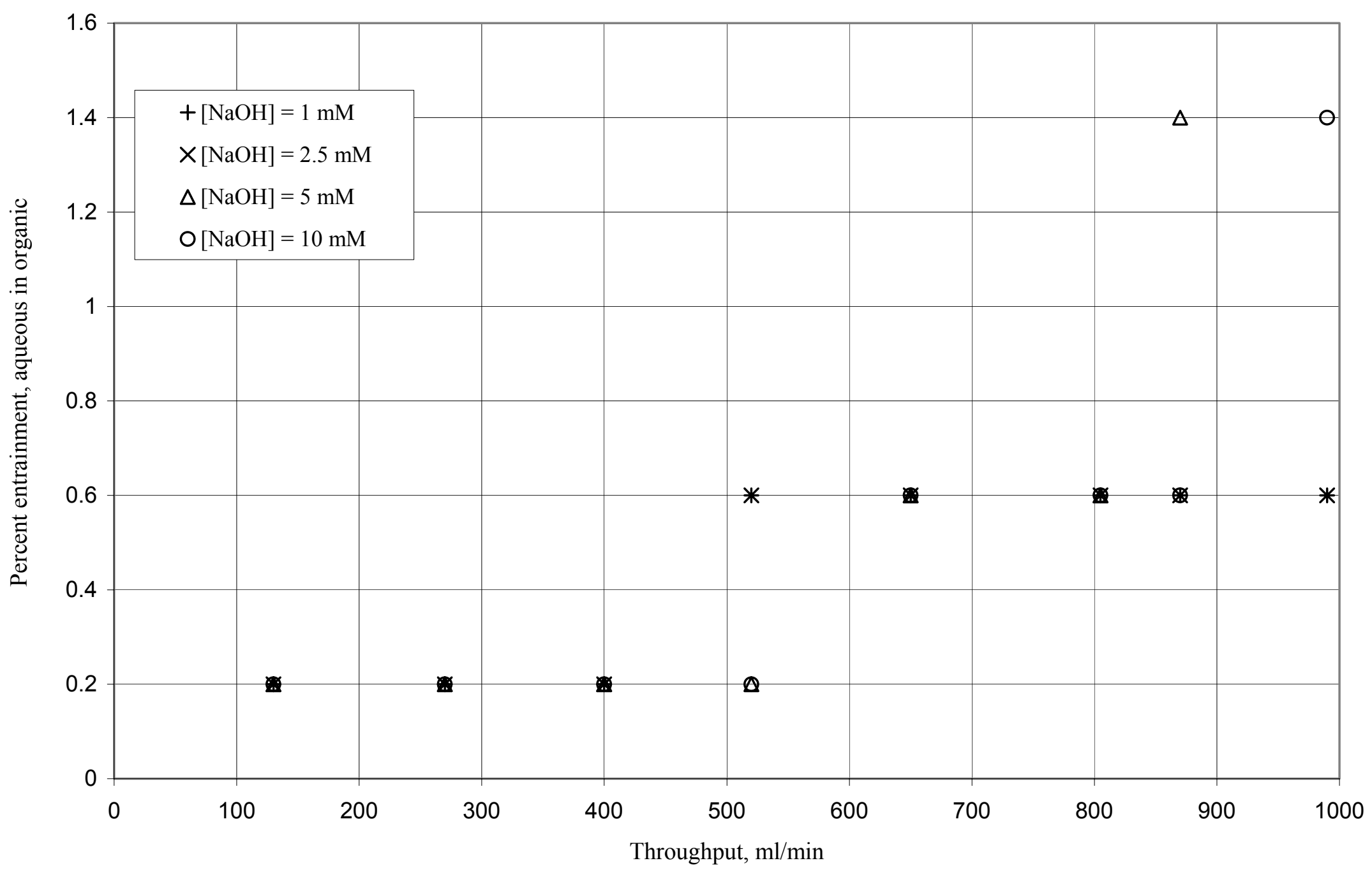

Fig. 4. Hydraulic performance at $4000 \mathrm{rpm}, \mathrm{O}: \mathrm{A}=5.0$ 


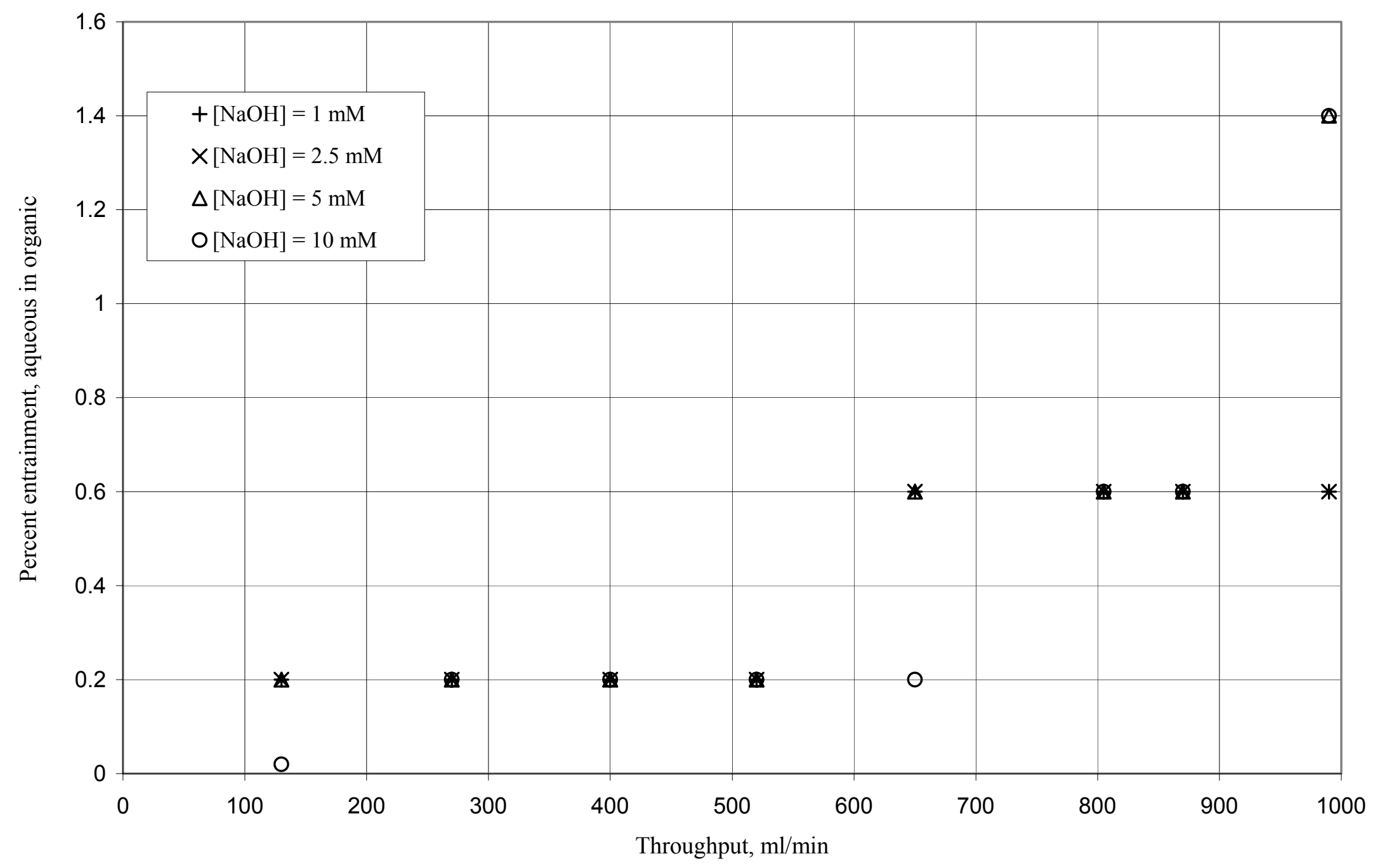

Fig. 5. Hydraulic performance at $3600 \mathrm{rpm}, \mathrm{O}: \mathrm{A}=5.0$ 


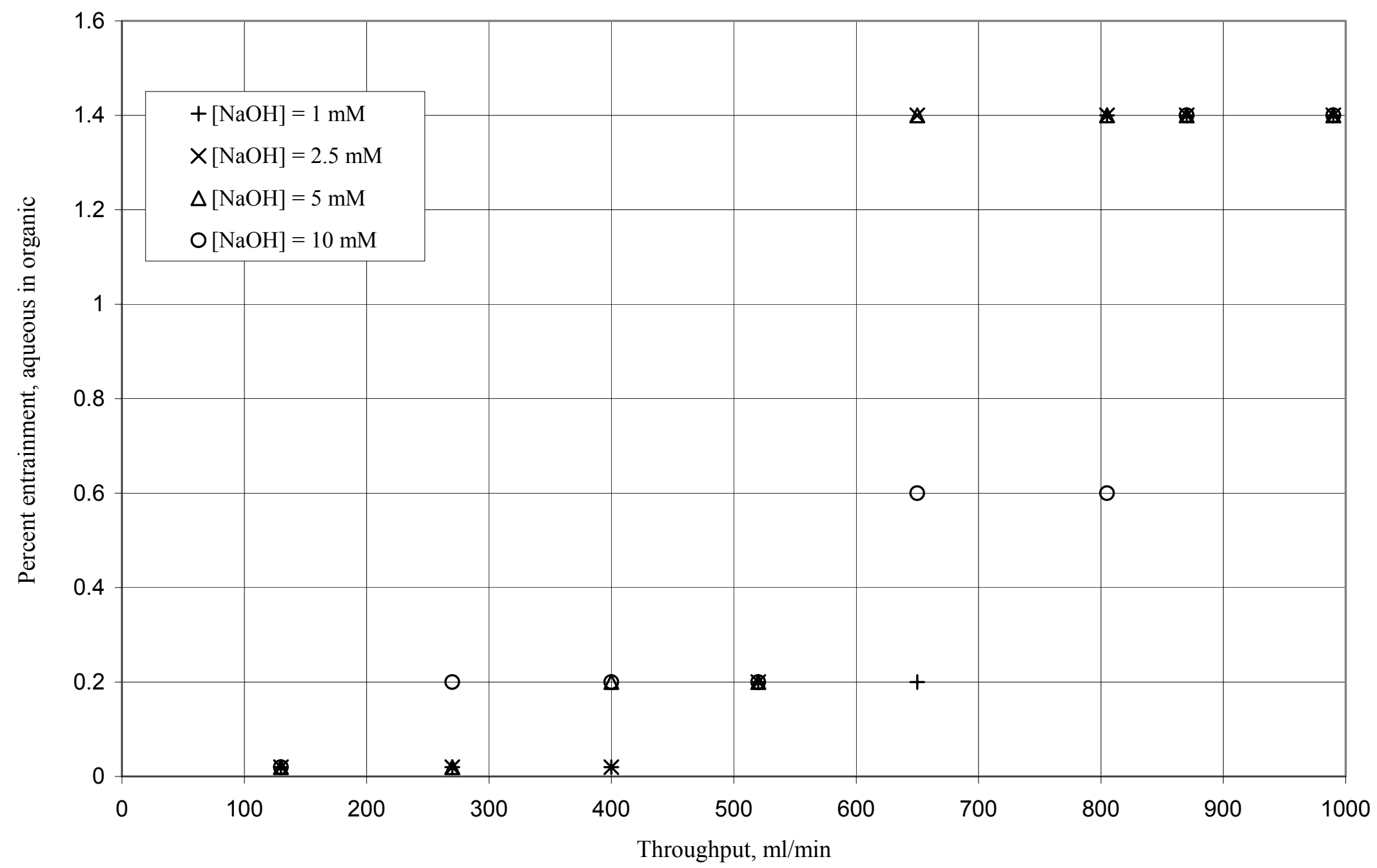

Fig. 6. Hydraulic performance at $3200 \mathrm{rpm}, \mathrm{O}: \mathrm{A}=5.0$ 


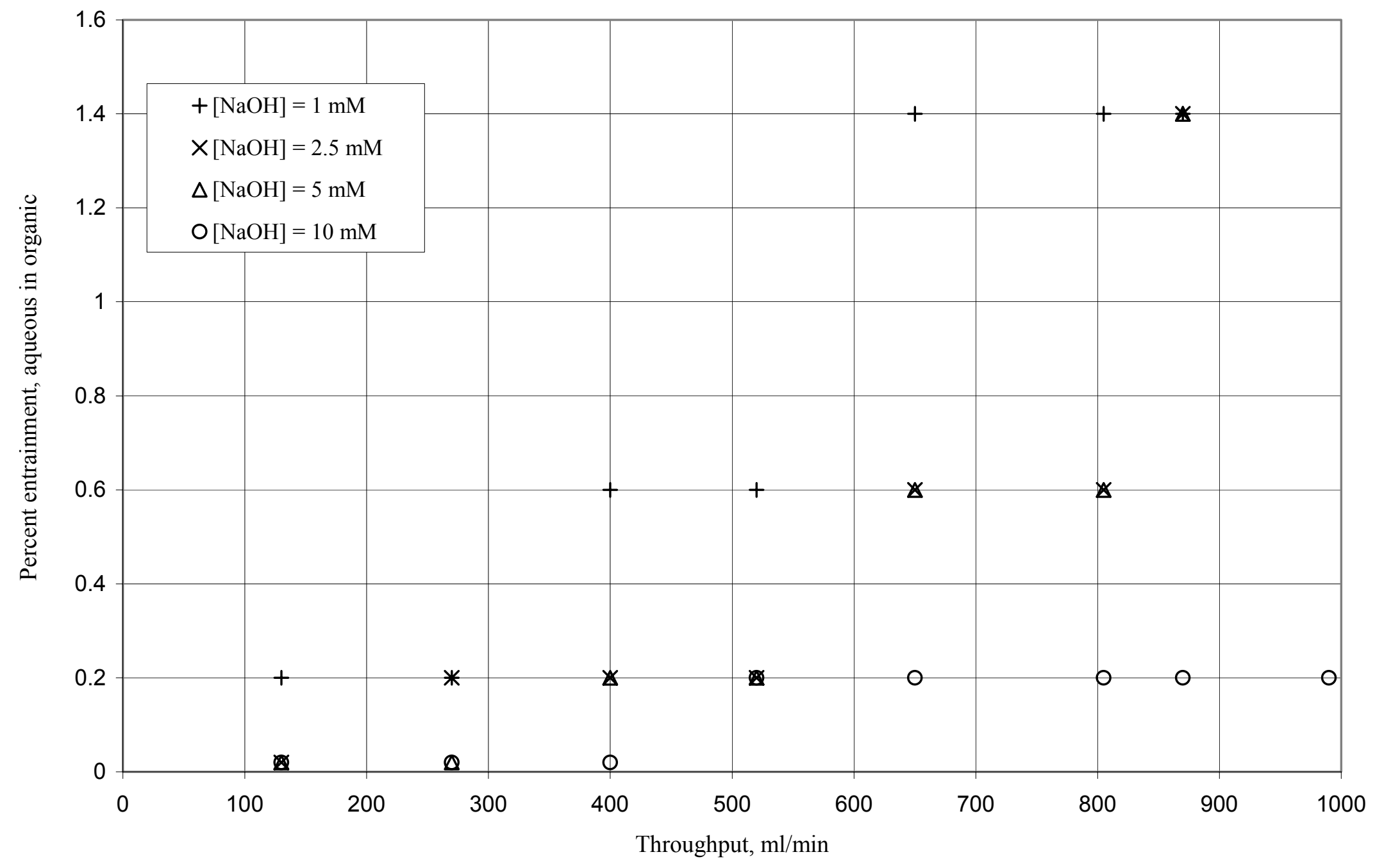

Fig. 7. Hydraulic performance at $4400 \mathrm{rpm}, \mathrm{O}: \mathrm{A}=2.0$ 


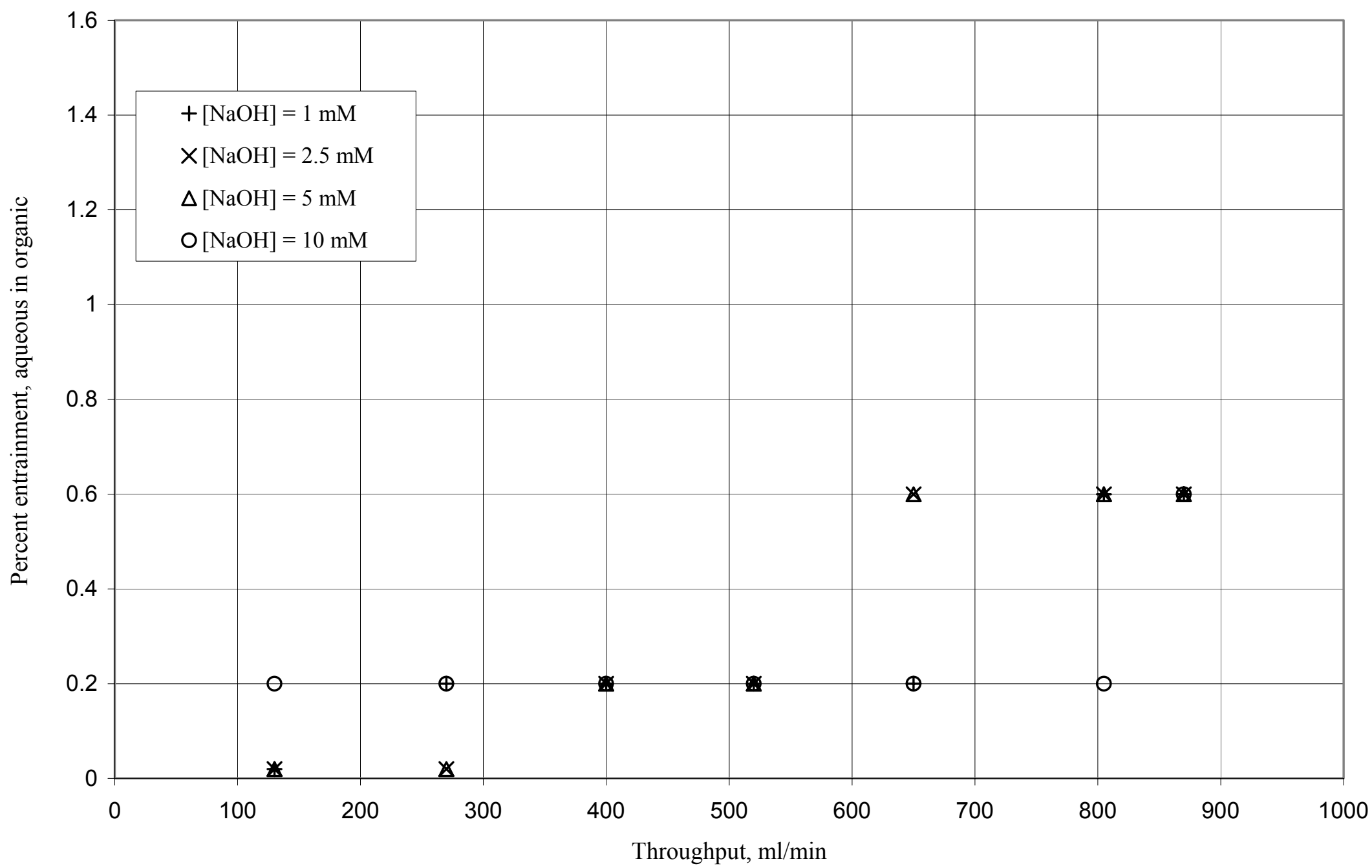

Fig. 8. Hydraulic performance at $4000 \mathrm{rpm}, \mathrm{O}: \mathrm{A}=2.0$ 


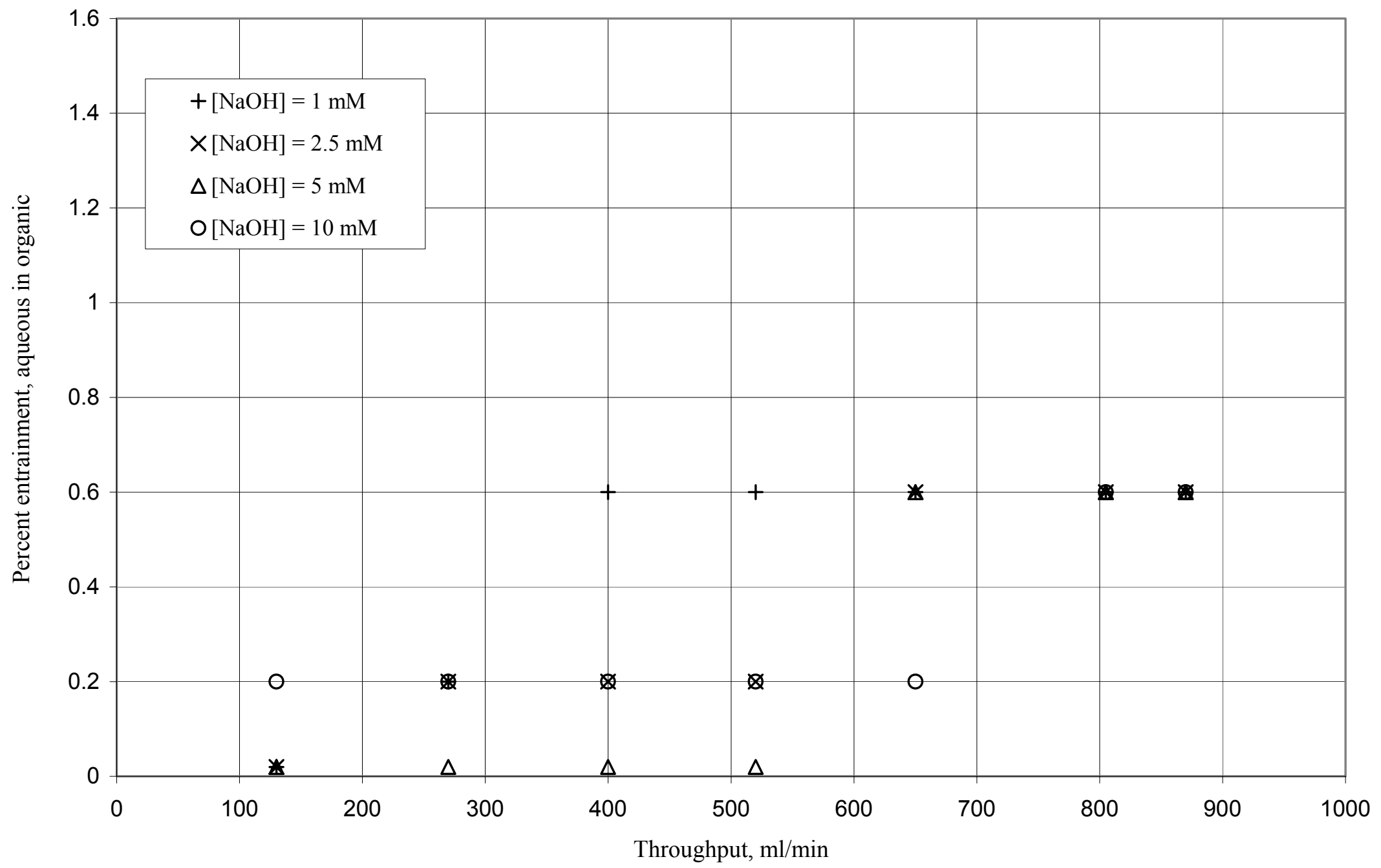

Fig. 9. Hydraulic performance at $3600 \mathrm{rpm}, \mathrm{O}: \mathrm{A}=2.0$ 


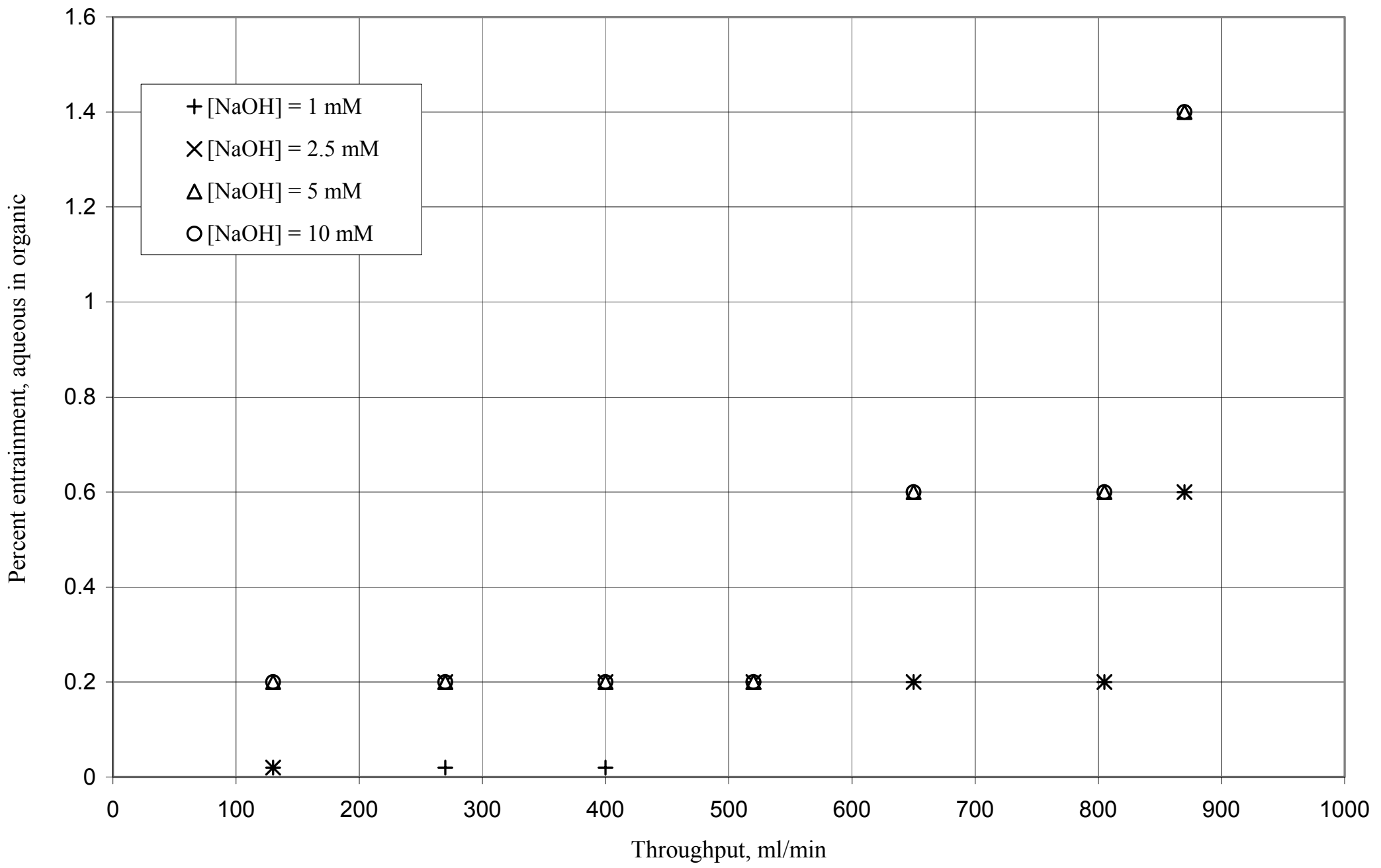

Fig. 10. Hydraulic performance at $3200 \mathrm{rpm}, \mathrm{O}: \mathrm{A}=2.0$ 
$\mathrm{mL} / \mathrm{min}$. The onset of foam plugging was delayed when the O:A value was 5.0 , as is indicated by the presence of higher throughput data points in Figs. 3 through 6. However, in most of these instances, the level of aqueous contamination in the organic effluent exceeded the $1 \%(\mathrm{v} / \mathrm{v})$ acceptance criteria.

At the higher O:A condition (5.0), phase separation is favored at lower $\mathrm{NaOH}$ concentrations. In Figs. 3 through 5, the acceptance limit of 1\% entrainment was first encountered at the higher $\mathrm{NaOH}$ concentrations as the throughput was increased. However, over a fairly wide range of throughputs up to about $800 \mathrm{~mL} / \mathrm{min}$, the effect of $\mathrm{NaOH}$ concentration on phase separation was minimal.

Where differences exist, the higher $\mathrm{NaOH}$ concentrations produce slightly better phase separation at the lower O:A value (2.0).

Results obtained at a rotor speed of $4400 \mathrm{rpm}$ are suspect. All other variables being equal, there is no apparent reason for contamination in the organic effluent to be greater at $4400 \mathrm{rpm}$ than at 4000 or $3600 \mathrm{rpm}$. During checkout of the contactor prior to the pretreatment of solvent under CSSX flowsheet conditions, an observation was made that carryover of aqueous solution in the organic discharge occurred at high rotor speeds (>4600 rpm) while no carryover was observed at lower speeds under identical flow conditions. It is suspected that the carryover phenomena is the result of aqueous feed solution being "atomized" by impinging on the rotor and then being thrown upward into the organic collector ring.

\section{DISCUSSION}

Because of the number of variables present, it is difficult to draw specific conclusions regarding phase separation from the dispersion numbers listed in Table 4. However, two general conclusions are apparent. First, dispersion numbers tend to be reduced (i.e., phase separation is retarded) when the DOA concentration is at the higher level. Second, the null test condition produced one of the higher dispersion number results. This result is likely due to the absence of degradation products. The apparent ease of phase separation under the null condition may also reflect the presence of co-extracted nitric acid that is only slightly neutralized at the lower $\mathrm{NaOH}$ concentration condition. 
On the basis of the calculated contrasts (Table 5), the significance of DOA concentration and the $4 \mathrm{SBP} / \mathrm{NaOH}$ interaction are nearly equal in the influence they exert on phase separation. Despite the low dispersion number obtained for the treatment in which the $\mathrm{NaOH}$ concentration was the only high-level variable, $\mathrm{NaOH}$ concentration was not indicated to significantly affect phase separation in the ANOVA results. This finding may be attributed to the fact the consistently low dispersion numbers were not obtained for treatments in which the $\mathrm{NaOH}$ concentration was high, nor were values consistently high when $\mathrm{NaOH}$ was present at low levels. The lack of significance of $\mathrm{NaOH}$ concentration is supported by the contactor hydraulic results.

The solvent used in the contactor test was spiked with high levels of 4SBP and DOA on the basis of the indicated significance of the DOA single-factor effect and the $4 \mathrm{SBP} / \mathrm{NaOH}$ interaction. It is recognized that in CSSX applications, the presence of these degradation products would be accompanied by some depletion of their precursors, Cs-7SB and trioctylamine. The presence of both the degradation products and precursors at high levels represents a compromise that was made to facilitate solvent preparation and equilibration under CSSX flowsheet conditions. Because neither the 4SBP nor the DOA concentrations were varied in the contactor hydraulic test, no correlations between contactor test results and the ANOVA results pertaining to these variables can be established. Results in Table 4 indicate that dispersion numbers were generally depressed when DOA was present; therefore, the presence of DOA in the solvent used in contactor testing should represent a conservative condition. The lack of any trend in dispersion number with respect to the presence of 4SBP and the ANOVA results both indicate that this component should not affect contactor performance.

Discounting the inconsistent contactor test results at a rotor speed of $4400 \mathrm{rpm}$, the results of this test tend to support the ANOVA finding of a significant NaOH/O:A interaction effect. At the higher O:A ratio, there is an indicated difference in the level of entrainment, which corresponds to differences in $\mathrm{NaOH}$ concentration (Figs. 4 and 5). However, at the lower O:A ratio, little correlation is observed between $\mathrm{NaOH}$ concentration and phase separation performance (Figs. 8 and 9). The interaction effect between $\mathrm{NaOH}$ concentration and $\mathrm{O}$ :A ratio may result from increased interaction between the aqueous hydroxide ion and the solvent when the aqueous-phase ion 
concentration is elevated and the volume of solvent available for counterion interaction is greater. Similarly, it is suspected that the interaction effect between 4SBP and $\mathrm{NaOH}$ concentration reflects interaction between hydroxide groups in the caustic and the phenol.

The observation of foaming in the organic discharge line at higher flow rates is consistent with observations made in earlier CSSX tests involving the use of a $5-\mathrm{cm}$ contactor. ${ }^{7}$ In these previous tests, the onset of foam plugging was found to be affected by the slope and length of the discharge line. In the reported test, the discharge line was sloped away from the contactor at an angle of approximately $45^{\circ}$. It is likely that some mitigation of foaming will occur if closely coupled contactors are used in solvent washing. Installation of oversized lines between wash stages would also be prudent, and installation of an insert in the line to promote foam coalescence should be considered as well. During testing under several sets of conditions, foam samples were collected at the onset of foam plugging. Without exception, the samples were found to contain the same levels of aqueous contamination that were in samples collected at the highest throughput value achieved before plugging occurred. Therefore, it is concluded that contamination of the organic effluent was not the cause of the foaming problem.

Both aqueous and organic samples collected after foam plugging had been under way for several minutes showed $>10 \%$ cross-phase contamination. After centrifugation, samples of both phases were found to contain an emulsion-like layer located at the phase boundary. The emulsions were separated only after extended periods of batch centrifugation. It should be noted that emulsification occurred only when conditions resulted in foam plugging of the organic discharge line, and only when operation was continued after plugging to the point that foam was observed in the aqueous discharge line as well.

\section{CONCLUSIONS}

Results of the two tests reported indicate that the effects of degradation products, O:A ratio, and $\mathrm{NaOH}$ concentration on phase separation performance are limited. However, the concentration of DOA, the interaction effect between $\mathrm{NaOH}$ and 4SBP, and the interaction effect between $\mathrm{NaOH}$ and O:A are statistically significant. Over the ranges of the variables considered, acceptable phase separation performance was achieved in a 5- 
cm contactor at throughputs up to approximately $750 \mathrm{~mL} / \mathrm{min}$. At the lower O:A value considered, the throughput-limiting factor was the formation of foam plug flow in the organic discharge line. While the onset of foam plugging was delayed at the higher O:A value applied in testing, phase separation performance under higher O:A conditions was less favorable than at the lower value.

Overall, the reported study indicates that solvent washing hydraulics are acceptable at the low concentrations of $\mathrm{NaOH}$ that are most favorable for removal of surfactant contaminants. This conclusion is derived despite the presence of the principal degradation products 4SBP and DOA at concentrations that are expected only after extended periods of irradiation. Acceptable hydraulic performance is achievable over a range of contactor speed and throughput conditions, and emulsion formation has been found to occur only under off-normal conditions. Consequently, the primary consideration in the determination of conditions to be applied in the washing of CSSX solvent can, and should, be the degree of contaminant removal; hydraulic performance limitations can be addressed by giving proper consideration to these limitations during equipment and flowsheet design. 


\section{REFERENCES}

1. R. A. Leonard, et al., Multi-Day Test of the Caustic-Side Solvent Extraction Flowsheet for Cesium Removal from a Simulated SRS Tank Waste, ANL-02/11, Argonne National Laboratory, Argonne, Ill., January 2002.

2. Department of Energy, "Record of Decision: Savannah River Site Salt Processing Alternatives," Fed. Regist. 66(201), 52752-52756 (October 17, 2001).

3. J. F. Birdwell, Jr., and K. K. Anderson, Evaluation of Mass Transfer Performance for Caustic-Side Solvent Extraction of Cesium in a Conventional 5-cm Centrifugal Contactor, ORNL/TM-2001/278, Oak Ridge National Laboratory, Oak Ridge, Tenn., January 2002.

4. R. A. Peterson, Preparation of Simulated Waste Solutions for Solvent Extraction Testing, WSRC-RP-2000-00361, Westinghouse Savannah River Company, Aiken, S.C., May 2000.

5. V. L. Anderson and R. A. McLean, Design of Experiments, Marcel Dekker, Inc., New York, 1974.

6. R. A. Leonard, S. B. Aase, H. A. Arafat, J. R. Falkenberg, and G. R. Vandegrift, Proof-of-Concept Flowsheet Tests for Caustic-Side Solvent Extraction of Cesium from Tank Waste, ANL-00/30, Argonne National Laboratory, Argonne, Ill., November 2000.

7. R. D. Spence, L. N. Klatt, L. H. Delmau, F. V. Sloop, Jr., P. V. Bonnesen, and B. A. Moyer, Batch-Equilibrium Hot-Cell Tests of Caustic-Side Solvent Extraction (CSSX) with SRS Simulant Waste and Internal ${ }^{137}$ Cs Irradiation, ORNL/TM-2001/49, Oak Ridge National Laboratory, Oak Ridge, Tenn., September 2001.

8. R. A. Leonard, "Solvent Characterization Using the Dispersion Number," Sep. Sci. Technol. 30, 1103-22 (1995).

9. O. L. Davies, ed., The Design and Analysis of Industrial Experiments, Longman, Inc., New York, 1978.

10. J. F. Birdwell, Jr., and K. K. Anderson, Evaluation of 5-cm Centrifugal Contactor Hydraulic and Mass Transfer Performance for Caustic-Side Solvent Extraction of Cesium, ORNL/TM-2001/137, Oak Ridge National Laboratory, Oak Ridge, Tenn., August 2001. 